\title{
LUIZ DE ANHAIA MELLO: UM PENSAMENTO CONSTITUÍDO POR "DIVERSOS MUNDOS QUE SE TOCAM E SE INTERPENETRAM"
}

\author{
Jhoyce Póvoa Timóteo \\ Mestrado em História - Universidade Estadual de Campinas
}

Luiz de Anhaia Mello quando se questionava sobre o tamanho ideal de cidade, de modo que ela alcançasse uma vida social plena, recorria à frase do sociólogo norte-americano Robert Erza Park, que definia a metrópole como "um mosaico de pequenos mundos que se tocam mas não se interpenetram" (MELLO, 1945: 272). Assim como Robert Park, acreditava que a vida nos grandes centros urbanos dificultava o contato mais próximo entre as pessoas, que se fechavam em seu mundo particular, sem tomar conhecimento da vida coletiva.

A partir de preocupações como o acelerado crescimento da cidade de São Paulo e a rotina de intenso trabalho nas grandes cidades, no ano de 1929, Anhaia Mello publica o artigo "Urbanismo: o recreio ativo e organizado das cidades modernas" (MELLO, abr. 1929). Este trabalho tem como tema central o sistema geral de recreio ativo e organizado das cidades modernas, baseado na premissa de que um dos principais objetivos do urbanismo moderno era restabelecer o contato entre o homem e a natureza.

Para que a natureza estivesse presente no espaço da cidade, Anhaia Mello apontava duas direções, os urbanistas partidários da idéia de levar a cidade para o campo, com a implantação de cidades-jardins ou cidades regionais, e aqueles que acreditavam que a solução para este dilema seria levar o campo para a cidade, organizando um sistema de recreio. Por considerar difícil, num futuro próximo, a adaptação da cidade de São Paulo aos princípios de organização da cidade-jardim, devido a interesses imobiliários e financeiros já estabelecidos na capital paulista, defendia a implantação de um sistema de recreio ativo e organizado como uma solução provisória e rápida para trazer o campo para a cidade.

Este sistema de lazer, segundo Anhaia Mello, deveria ser incorporado aos serviços básicos oferecidos pelas municipalidades, como o sistema de distribuição de água, de esgoto, de transporte coletivo. Entretanto, não bastava existirem 
áreas disponíveis para sua incorporação no plano geral da cidade, pois não se tratava apenas de problema de extensão, mas de distribuição e uso adequado. A eficiência do recreio ativo e organizado estava ligada à acessibilidade destes espaços, com uma distribuição que beneficiasse todas as classes sociais, conseguindo ser útil a indivíduos de todas as idades. Um de seus objetivos era suavizar o cotidiano nos grandes centros urbanos, pois, segundo Anhaia Mello:

A cidade moderna criou vários problemas.

Os inconvenientes são de toda a ordem. Não é apenas o empilhamento urbano ou a falta de contato com a natureza. Os processos modernos de especialização industrial, por exemplo, anulam a imaginação, a iniciativa e os impulsos criadores da individualidade (MELLO, abr. 1929: 146).

A preocupação com a democratização destes espaços de lazer estava relacionada com os efeitos psicológicos positivos a eles associados. Além de proporcionar aos cidadãos uma maior participação na vida em sociedade, atuava na harmonização dos "impulsos humanos", desgastados pela árdua rotina de trabalho ou mesmo pelo esforço em tornar-se sociável, o que para Anhaia Mello significava abdicar de um posicionamento individual em relação à vida, visando uma pacífica convivência em grupo.

Sendo assim, o sistema de recreio ativo e organizado era fundamental à sociedade por se tratar de um antídoto à civilização, pois permitia que seus freqüentadores resgatassem hábitos de vida não incorporados pela cidade industrial. Anhaia Mello afirmava que:

Os objetivos do recreio são uns imediatos, como a atividade; outros intermediatos, como a formação de hábitos e atitudes e afinal remotos alguns, como a formação do caráter e do cidadão útil à pátria.

O recreio não é uma atividade inútil; é, pelo contrário, uma coisa séria para todos, mormente para a criança.

A criança brinca; o brinquedo cria, faz. Recreio é termo que se deve reservar para o adulto porque recrear é refazer as energias gastas. (MELLO, abr. 1929: 149)

Devido à importância do tema no conjunto de suas considerações a respeito das efetivas soluções para os problemas enfrentados pelas cidades modernas, Anhaia Mello retoma sua proposta de recreio ativo e organizado ao longo de suas publicações $^{1}$.

\footnotetext{
1 Este tema também está presente nos artigos em que Anhaia Mello discute a legislação do urbanismo, na cidade de São Paulo, defendendo que parte dos lucros decorrentes da implantação
} 
Em seu artigo "A Cidade Jardim" (MELLO, 1947), publicado em 1947, enfatiza novamente que $\mathrm{O}$ ideal seria as cidades se adaptarem aos princípios urbanísticos da cidade-jardim, ao invés de procurar soluções paliativas para o problema da falta de espaços verdes. A cidade-jardim era sinônimo, para este engenheiro-arquiteto, de planejamento inteligente, que não fazia uso do "custosíssimo urbanismo cirúrgico nos centros supercongestionados"2.

No ano de 1955, no artigo "Visão do futuro e realidade do presente" (MELLO, 1955), volta às características da cidade-jardim para fundamentar suas idéias sobre planejamento urbano, destacando a importância de um Plano Regional de longa base. As cidades deveriam ser pensadas como parte orgânica de um grupo social, pois não se tratavam de uma área administrativa arbitrária. Anhaia Mello destaca que o plano seria meio para um fim, e que o verdadeiro fim, a razão de ser da cidade, era o bem estar da população, "[...] a liberação das suas energias para o trabalho criador, um standard de vida elevado, generalizado, seguro. 'All things for all men' 'Tudo, para todos'"' (MELLO, 1955: 02). Devido à sua admiração pelo projeto de cidade-jardim, recorrentemente citava o livro Cidades-jardins de amanhã (HOWARD, 1996), publicado pelo inglês Ebenezer Howard em 1898, destacando o impacto positivo do tamanho definido e definitivo destas cidades sobre sua população, pois tornava o espaço urbano compatível à escala humana.

O crescimento acelerado e descontrolado da cidade de São Paulo trazia também a preocupação com o impacto psicológico da adaptação à vida neste grande centro urbano. Desta forma, o recreio ativo e organizado atuaria na suavização dos impasses emocionais ocasionados por esta nova experiência de vida. A adaptação humana à cidade moderna mereceu atenção de Anhaia Mello, que encontrou na Sociologia Urbana norte-americana um importante referencial teórico. Segundo Otávio Guilherme Velho, em seu livro O Fenômeno Urbano:

[...] a idéia de uma Sociologia Urbana teria surgido não de uma preocupação acentuada de elaboração teórica, o que exigia um extremo rigor lógico na definição da ciência, mas da necessidade de enfrentar certos problemas 'práticos'

\footnotetext{
das taxas de benefícios, cobradas de moradores beneficiados por alguma melhoria urbana financiada pelo poder público, fosse destinada ao financiamento destas áreas de lazer. Também está presente nos artigos sobre a regulamentação dos serviços de utilidade pública, pois Anhaia Mello acreditava que era responsabilidade do Estado oferecer opções de lazer "saudável" à população.

2 Forma pela qual se referia às intervenções na cidade de São Paulo, cujo objetivo maior era viabilizar o seu crescimento.
} 
urgentes ligados ao enorme crescimento das grandes cidades que acompanha a industrialização e o desenvolvimento capitalista, especialmente nos Estados Unidos, com a imigração em massa de contingentes europeus em fins do século XIX e início do século XX.

Esse crescimento traz consigo uma série de fenômenos desconhecidos até então, pelo menos em tal escala, inclusive manifestações de 'patologia social' tais como sub-habitação, delinqüência, marginalismo e choque cultural, bem como problemas de planejamento urbano em geral. É em resposta a esses desafios que se desenvolve a Sociologia Urbana. (VELHO, 1976: 07-8)

Anhaia Mello, em sua produção sobre Urbanismo, assim como em sua proposta de sistema de lazer, utilizava em sua argumentação autores norte-americanos que no início do século vinte estavam discutindo os problemas das cidades modernas na perspectiva da Sociologia Urbana e procuravam soluções que não se restringiam às explicações "puramente" técnicas. Otávio Velho elege, em seu livro, os autores Robert Park e Louis Wirth como representantes da chamada "Escola de Chicago" e Georg Simmel como teórico de grande representatividade para estes, sendo todos eles citados por Anhaia Mello. Esta referência se faz na tentativa de compreender a perda do sentido da vida em comunidade ocorrida na cidade industrial.

Apesar de utilizar diversificada referência bibliográfica em seus artigos, Anhaia Mello recorre freqüentemente à experiência norte-americana, sempre destacando o exemplo bem sucedido deste país na área de Urbanismo. Os Estados Unidos seriam o país que aplicava da melhor forma os verdadeiros princípios do urbanismo moderno, por terem desenvolvido bons dispositivos administrativos e possuírem uma população com espírito cívico bastante acentuado.

Contudo, uma questão freqüentemente retomada por Anhaia Mello, em seus artigos, era a importância de se adaptar as soluções urbanísticas às especificidades locais. Quando discute a relação entre legislação e urbanismo, em "A Cidade, problema de governo" (MELLO, 1928), afirma:

Nos Estados Unidos, porém, terra da standardização, não há um tipo standard de governo de cidade.

Nem há mesmo sequer um tipo estadual, Californiano ou Novaiorquino.

[...] Esta política é muitíssimo inteligente porque não deve haver uniformidade de organização municipal onde não haja igualdade de condições e de problemas e não há duas 
cidades que se possam dizer iguais, física, econômica ou socialmente.

E se essas condições mudam, a forma de governo também muda. (MELLO, 1928: 279)

Portanto, as leis, consideradas por este engenheiro-arquiteto um fator de realização do urbanismo, deviam adequar-se às condições locais, sendo elaboradas para melhor atender aos problemas que deveriam solucionar. As diretrizes do urbanismo norte-americano teriam, assim, que se ajustar às questões das cidades brasileiras, o que descaracterizaria a simples transposição de um modelo.

O urbanismo norte-americano seria, para Anhaia Mello, mais um exemplo de procedimento a ser seguido, do que um esquema administrativo a ser implantado mimeticamente. Se o Brasil deveria seguir o modelo adotado pelas cidades norte-americanas para resolver seus problemas, seria mais no sentido de garantir maior investimento financeiro e técnico por parte dos governos, de adotar princípios que levassem a uma cidade mais orgânica, pautados no projeto das cidades-jardins, do que na direção de aplicar no país o urbanismo praticado nestas cidades.

Ao discutir o problema da habitação nos Estados Unidos, Anhaia Mello compara a situação norte-americana e a brasileira em termos governamentais, e ressalta que, além dos norte-americanos desenvolverem pesquisa na área, para conhecer com detalhes a situação de seu país, estavam empenhados em criar um plano definitivo para acabar com o problema da habitação para as camadas populares. No Brasil, eram oferecidas apenas medidas paliativas para este setor. A utilização de métodos ineficientes e a escolha de caminhos equivocados eram as falhas brasileiras.

Não havia, portanto, a intenção de que os exemplos norte-americanos fossem simplesmente imitados. O que ocorria era o desejo do urbanismo ser encarado, no Brasil, a partir da perspectiva daquele país, e que desenvolvesse aqui um sentimento cívico de intensidade semelhante. As estratégias de atuação poderiam ser as mesmas, pois os fins do Urbanismo eram universais, mas deveriam se adequar às particularidades de cada cidade.

Desta forma, se os estudos realizados nos Estados Unidos pretendiam descobrir a solução para o problema das habitações das massas de baixos salários, estas pesquisas serviriam, na opinião de Anhaia Mello, para todos os 
países de crescimento rápido, onde os problemas sociais se agravavam, como o caso do Brasil. Os norte-americanos estavam a caminho de assegurar ao cidadão um padrão mínimo de moradia, para que ele pudesse vir a ser útil à sociedade, pois "Tão necessária como a educação é a habitação salubre e digna, porque um padrão mínimo de lar para todas as famílias não é apenas indispensável para a higiene das comunidades mas também para a estabilidade social e econômica das nações" (MELLO, jan. 1936: 162).

Ainda em relação ao problema da habitação popular, Anhaia Mello retoma a idéia de que as soluções urbanísticas precisavam se adaptar às necessidades locais. De acordo com este engenheiro-arquiteto, "A habitação é essencialmente um problema local, pois que depende de condições locais que variam largamente, de estado a estado, e de cidade; tais como o clima, hábitos de vida, caráter e composição das populações e respectivas ocupações, crescimento urbano e seu controle pelo urbanismo" (MELLO, abr. 1936: 119).

Sendo assim, ao adotar como referencial o urbanismo norte-americano, Anhaia Mello não deixava de considerar como fator relevante as diferenças culturais e políticas existentes entre os dois povos e os dois países. Ao salientar, portanto, no decorrer de toda sua produção, a necessidade da propaganda para conseguir formar na população uma consciência cívica, apostava que, apesar de se tratarem de países distintos, a mensagem do "verdadeiro urbanismo" seria capaz de apaziguar eventuais conflitos culturais. Sua referência aos métodos norte-americanos não se fundamentava na imposição de um modelo, mas na crença de haver caminhos únicos que levavam à resolução dos problemas da cidade moderna. Para Anhaia Mello, os Estados Unidos haviam descoberto o caminho antes do Brasil.

Assim, em "Os parques estaduais americanos" (MELLO, set. 1929), Anhaia Mello refere-se ao tema do recreio ativo e organizado para destacar a importância dos espaços de recreação e o empenho dos estados norte-americanos em disponibilizar áreas para este fim, demonstrando a diferença de abordagem no Brasil. Desta forma, seu principal argumento sobre esta questão era que, "Quando, em futuro não remoto, se adensarem as populações, estas áreas prestarão ainda maiores serviços, reservadas que estão, ao uso e gozo das futuras gerações" (MELLO, set. 1929: snp). O Brasil estava, 
portanto, muito aquém da preocupação norte-americana com os espaços de lazer.

Os urbanistas brasileiros, assim como os norte-americanos, deveriam tratar os problemas referentes aos parques e às áreas de recreio com o mesmo empenho, tornando-o tema de discussão nacional. Essa seria mais uma das lições que o urbanismo praticado nos Estados Unidos teria a ensinar sobre o recreio ativo e organizado. Este sistema de lazer merecia atenção nacional devido à sua capacidade de repor as energias gastas durante o dia de trabalho.

Além disso, a referência ao Urbanismo norte-americano tinha relação com método de pesquisa adotado por este engenheiro-arquiteto que considerava que "[...] o urbanismo, mais que qualquer ciência é um saber de experiência feito'" (MELLO, 1929: 43). Desta maneira, Anhaia Mello indicava que suas formulações teóricas pautavam-se no empirismo, ou seja, no factível, naquilo que já fora provado possível de realizar. Segundo ele, os Estados Unidos haviam superado, em um passado não muito distante, dificuldades de crescimento parecidas com as enfrentadas pelo Brasil, naquele momento. Anhaia Mello, portanto, embasava suas argumentações em defesa do exemplo norte-americano no recente processo de industrialização deste país em comparação com a Europa, assim como nas suas "jovens" cidades se pensadas em relação às existentes no "Velho Mundo".

Entretanto, essa forma de análise não era característica apenas deste engenheiro-arquiteto, mas fazia parte do método científico vigente em sua época. Victor da Silva Freire, em seu artigo "Melhoramentos de S. Paulo" (FREIRE, 1911), publicado na Revista Politécnica, afirmava que:

\begin{abstract}
A era do industrialismo foi que criou este estado de coisas, e nós somos dos últimos a sentir-lhe as conseqüências. Aproveitemos dessa circunstância para utilizarmos a experiência dos que nos precederam. Na mesma ordem de idéias manda o bom censo que observemos os que melhor resolveram os seus problemas e aqueles cujas condições mais se assemelham às nossas (FREIRE, 1911: 93).
\end{abstract}

Embora este engenheiro considerasse que São Paulo encontraria na Europa seus problemas em termos idênticos, não nos Estados Unidos, várias de suas idéias são encontradas nos artigos de Anhaia Mello, como a importância do "urbanismo preventivo" em contraposição ao "urbanismo cirúrgico", a 
necessidade do Governo Municipal não ser afetado por disputas políticas, a adequação das leis às necessidades das cidades modernas, destacando o papel das taxas de melhoria. A valorização dos sistemas de parques e recreio e seus benefícios para a formação do cidadão útil à pátria também é um tema comum a estes dois autores. No entanto, neste assunto, Victor da Silva Freire faz referência à experiência norte-americana, pois este país havia compreendido a verdadeira importância desses espaços para a vida nas grandes cidades.

Além das áreas de engenharia e arquitetura, as idéias norte-americanas também encontraram seu espaço em outras ciências como a higiene pública e o sanitarismo. Cristina Campos, em seu livro São Paulo pela lente da higiene: as propostas de Horácio de Paula e Souza para a cidade (1925-1945) (CAMPOS, 2002), discute a forte relação das propostas de Paula e Souza no Código Sanitário para a cidade de São Paulo, do ano de 1925, e sua pós-graduação nos Estados Unidos, além do patrocínio da Fundação Rockefeller às iniciativas do setor de higiene por todo o estado paulista. Segundo a autora:

Em 1922, assume a direção do serviço sanitário o médico sanitarista Geraldo Horácio Paula Souza, recomendado ao secretário dos Negócios do Interior pela fundação Rockefeller. Ao retornar dos Estados Unidos, em 1922, após a conclusão de seu curso de doutorado [...], assumiria também a direção do Instituto de Higiene e do Serviço Sanitário.

Geraldo Paula Souza retornou ao Brasil com novos ideais e metodologias na área da higiene e da saúde pública, e estes ficaram patentes em seu primeiro relatório como diretor do Serviço Sanitário ao secretário dos Negócios do Interior. Nesse relatório, [...] o médico expõe todas as suas doutrinas, bem como sua aversão ao modelo de saúde baseado no policiamento e nas campanhas sanitárias. O novo problema da saúde pública, para o médico, [...] [é] à vida moderna, urbana, (...) o nosso principal objeto, por ter conseqüências trágicas para a nossa sociedade em termos do processo saúde/doença'. As críticas também estão direcionadas '(...) para o atraso em que nos encontramos em relação à aplicação da ciência, em particular a Higiene, para a melhoria das condições de vida das pessoas. Ressaltou as experiências dos serviços de Saúde Pública em outros países, em particular nos Estados Unidos (CAMPOS, 2002: 50-1).

Cristina Campos afirma que muitas vezes a ligação com os propósitos sanitários norte-americanos causava problemas com profissionais que mantinham posturas mais tradicionais, originadas da Europa. Entretanto, 
considera que "Historiar a trajetória do Instituto de Higiene na sociedade paulista é interessante porque nos permite identificar o papel da influência norte-americana no campo da saúde pública" (CAMPOS, 2002: 59).

Trabalhar com a idéia de influência como um processo de mão única, em que uma das partes é beneficiada pelo acesso a um conhecimento já constituído e o reproduz indiscriminadamente desconsidera as possibilidades de atuação daquele que se apropria do conhecimento. Este passa por um processo de ressignificação, sendo interpretado a partir de novos filtros, que são resultado de diferenças culturais. O sistema de recreio ativo e organizado, apesar de sua estrutura de implantação ser baseada na experiência norte-americana, tem suas origens conceituais, de controle do tempo livre dos trabalhadores e resgate da vida em comunidade, para além de discussões surgidas com os Estados Unidos. Este país pode ter sistematizado essas idéias de modo a construir uma abordagem diferenciada, decorrente, entretanto, de referências teóricas que se interpenetram.

\section{Referências bibliográficas:}

CAMPOS, Cristina de (2002). São Paulo pela lente da higiene: as propostas de Horácio de Paula e Souza para a cidade (1925-1945). São Carlos: RiMa.

FELDMAN, Sarah (2005). Planejamento e Zoneamento. São Paulo: 1947- 1972. São Paulo: Editora da Universidade de São Paulo/Fapesp.

FREIRE, Victor da Silva (1911). Melhoramentos de S. Paulo. Revista Politécnica, fevereiro/março.

HOWARD, Ebenezer (1996). Cidades-jardins de amanhã. Tradução: Marco Aurélio Lagonegro. Introduação: Dacio Araújo Benedicto Ottoni. - São Paulo: HUCITEC, Estudos Urbanos: Série Arte e Vida Urbana.

MELLO, L. G. R. de Anhaia (1928). A cidade, problema de governo. Boletim do Instituto de Engenharia. São Paulo, n.43, dez.

MELLO, L. G. R. de Anhaia (1929). Problemas de Urbanismo: bases para a resolução do problema técnico. Boletim do Instituto de Engenharia, São Paulo. MELLO, L. G. R. de Anhaia (1929). Urbanismo: o recreio ativo e organizado das cidades modernas. Boletim do Instituto de Engenharia. São Paulo, n.47, abr. 
MELLO, L. G. R. de Anhaia (1929). Os parques estaduais americanos. Ilustração Brasileira. Rio de Janeiro, n.109, set.

MELLO, L. G. R. de Anhaia (1936). Um Programa de Habitação para os Estados Unidos. Revista Politécnica. São Paulo, n.121, jan./mar., p.162.

MELLO, L. G. R. de Anhaia (1936). Um Programa de Habitação para os Estados Unidos. Revista Politécnica. São Paulo, n.122, jan./mar.

MELLO, L. G. R. de Anhaia (1945). A Cidade, Base Material de Relações Sociais, Sociologia Urbana, Ecologia Humana e o Plano de Londres. Engenharia. São Paulo, n.31, mar.

MELLO, L. G. R. de Anhaia (1947). A Cidade Jardim. Digesto Econômico. São Paulo, n.36, nov.

MELLO, L. G. R. de Anhaia (1955). Visão do futuro e realidade do presente. Habitat. São Paulo, n.21, mar./abr.

VELHO, Otávio Guilherme (Org.) (1976). O Fenômeno Urbano. RJ: Zahar.

Texto recebido em: 26/09/2007. 